\title{
UM OLHAR GEOGRÁFICO SOBRE A CONSTRUÇÃO DO ATLAS MUNICIPAL E ESCOLAR DE RIO CLARO
}

\author{
M aria Silvia Almeida Carreiro*
}

\begin{abstract}
RESU M 0: 0 objetivo deste trabal ho foi o de realizar uma retrospectiva do processo de construção do Atlas M unicipal Escolar de Rio Claro. N esta trajetória foi possível reconhecer a importância do estudo da localidade, do domínio da linguagem do mapa e da integração entre as três formas de linguagem que estão presentes nas suas páginas: o mapa, a fotografia e o texto escrito. 0 desafio foi grande e viveu-se intensamente esse projeto desde a reflexão sobre as práticas docentes do grupo de professores-autores da rede pública de ensino até a aplicação das páginas nas escolas participantes.

Palavras-chave: Ensino de geografia. C onstrução de mapas. Atlas escolares. Formação de professores.
\end{abstract}

\section{A gEOGRAPHical LOOK ON THE ELABORATION OF THE MUNiCipal SCHOOL at LASES OF RIO ClaRo}

ABST RACT: This work aims at presenting a retrospective of the elaboration process of the Rio Claro M unicipal School Atlas. In this trajectory, one may recognize the importance of studying the locality, mastering the cartographic language and integrating the three forms of language present in its pages: maps, photographs and written texts. Such a big challenge was deeply experienced, from the reflections on the teaching practices of this group of public school teachers-authors that marked its beginning to its final use of the atlas pages in the participating schools.

Key words: Geography teaching. Elaborating maps. School atlas.

Teacher training.

Professora da rede estadual de ensino e dos cursos de Geografia e Ciências Sociais do Instituto Superior de Ciências Aplicadas, Limeira (SP). E-mail: msacarreiro@linkway.com.br 
projeto "Integrando U niversidade e Escola através da Pesquisa em Ensino" desenvolveu um material de ensino para os municípios de Rio Claro, Limeira e I peúna. Ele se voltou para o estudo da localidade e teve como finalidade desenvolver atlas escolares para alunos de terceira a sexta séries do ensino fundamental. 0 levantamento de documentos, dados e outras informações propiciou a produção de materiais como mapas, fotos, gráficos e textos.

0 convite feito pela professora doutora Rosângela $D$ oin de Almeida, da UnESP de Rio Claro, chegou no ano de 1996 e tinha como proposta a construção das páginas dos temas geográficos para 0 Atlas de Rio Claro. Em pesquisa anterior, nos debruçáramos sobre um trabalho, cuja finalidade era avaliar a importância do H orto Florestal de Rio Claro, hoje Floresta Estadual Edmundo $\mathrm{N}$ avarro de Andrade, na dinâmica ambiental de seu entorno.

Grandes mudanças e conflitos permeavam os ambientes escolares da rede pública de ensino, por conta da reestruturação ocorrida no Governo M ário Covas. No início daquele ano, eu havia sido transferida para a Escola Estadual "Professora H eloísa Lemenhe M arasca", após 13 anos na Escola Estadual "Professora C arolina Augusta Seraphim", local de trabalho de livre escolha, mas que iria a partir de 1996 concentrar alunos de primeira à quarta série.

Rio Claro é a cidade onde eu nasci e sempre morei.

Local de readaptações, o Grupo Atlas trouxe a oportunidade de troca de nossas vivências no cotidiano da sala de aula. Profissionais da disciplina de $\mathrm{G}$ eografia encontravam-se semanalmente com professores de H istória e Ciências de Rio Claro, Limeira e I peúna, com estagiários da graduação em G eografia da UN ESP e com a coordenadora do projeto, professora Rosângela.

O s atlas escolares dos três municípios começaram a ser pensados, discutidos e desenhados. D esenhados porque neles se colocavam os primeiros esboços, após anos e anos de busca de um material de ensino que possibilitasse conhecimentos mais concretos do espaço geográfico rio-clarense e de sua representação.

A princípio, os temas que iriam compor as páginas de G eografia foram escolhidos de acordo com o programa do ensino fundamental da Proposta Curricular para o Ensino da G eografia do Estado de São Paulo. Até então, eles só haviam sido tratados de maneira bastante reduzida nos livros didáticos ou por poucos professores, docentes das terceiras e quartas séries do ensino fundamental da rede pública de ensino. 
O s temas sugeridos pela proposta: 0 lugar de vivência do aluno e a escola como espaço de relação para o ciclo básico; A inserção do aluno no espaço brasileiro para a terceira série; A cidade e o campo: 0 elo através do trabalho para a quarta série; 0 processo de produção e a produção do espaço brasileiro para a quinta série; e 0 Brasil atual, suas desigualdades e inserção no mundo para a sexta série, demonstravam que o entendimento da realidade envolve sociedade-natureza, trabalho, relações sociais, a realidade física em si e a produção do espaço, que como processo requer análises de sua historicidade, bem como a necessidade de se entender o lugar no presente em um processo de idas e vindas, do mais próximo ao mais distante e vice-versa.

$\mathrm{N}$ a certeza de que o processo de construção dos conceitos de orientação, localização e representação espacial pelos alunos é feito de modo contínuo ao longo das oito séries do ensino fundamental, e com base nas sugestões e nos conteúdos da Proposta Curricular de Geografia, os temas escolhidos inicialmente pelo grupo de professores de geografia foram: Representação da Terra, O nde estamos na Terra, D ivisão político-administrativa, 0 s bairros de minha cidade, I migração, Expansão urbana, Indústria e Infra-estrutura urbana.

Alguns temas permaneceram e se transformaram em páginas para o atlas, outros não. Temas como Rede viária, Relevo, Serviços, Escolas, Saúde e Setores surgiram após muitas discussões e muitos meses de trabalho, no momento em que os Parâmetros Curriculares $\mathrm{N}$ acionais chegavam às nossas mãos.

$\mathrm{N}$ essa trajetória surgiu a oportunidade de reconhecer, mais uma vez, que a G eografia estuda as relações sociedade-natureza na busca de explicações para a organização do espaço, a qual tem raízes nas relações sociais de trabal ho. Por intermédio de uma releitura de M ilton Santos foi possível refletir sobre o espaço do lugar rioclarense como o somatório e a superposição de vários espaços nos quais se materializaram diferentes relações sociais.

A revisão bibliográfica de estudos relacionados com as metodologias da Geografia e da Cartografia foi necessária, bem como daquelas ligadas aos mapas e à semiologia gráfica (linguagem gráfica). U m curso de Cartografia Temática no ensino da G eografia foi ministrado para o Grupo Atlas pelo professor doutor Serge Bonin, do Laboratório de Graphique, da École des $\mathrm{H}$ autes Etudes em Sciences Sociales, de Paris, no mês de maio de 1997. 
Assim, foi possível compreender mais uma vez a importância do trabalho escolar sobre o estudo do espaço e sua representação (Almeida \& Passini, 1989); redescobrir a necessidade de realizar atividades em sala de aula, com os alunos de quinta e de sexta séries, que thes proporcionassem o domínio sobre o espaço por meio de sua representação espacial, utilizando os mapas do corpo e da sala de aula (Almeida, 1994); aprender que uma nova linguagem gráfica, isto é, o tratamento gráfico da informação, pode se constituir em um método dinâmico de ensino que auxilia a criança a construir o pensamento lógico a partir de uma forma visual que ela mesma elabora e que um mapa, além de ter diferentes utilidades, pode ser um exercício necessário para que os alunos cheguem às respostas de questões que lhes são propostas (Bertin \& Gimeno, 1982).

O domínio da linguagem do mapa é tão importante para o cidadão como o raciocínio numérico e a comunicação verbal. Três formas de linguagem integraram-se nos atlas escolares: o mapa, a fotografia e o texto escrito. Para Ferreira \& M artinelli (1995) o mapa é a representação gráfica reduzida e seletiva dos espaços, a fotografia pode melhor expor os conceitos geográficos e o texto constitui uma legenda explicativa das fotografias e dos mapas. ${ }^{1}$

Essas três formas de linguagem estiveram presentes nas páginas que, depois de elaboradas, eram apresentadas, observadas e discutidas nas reuniões do Grupo Atlas. Ả medida que cada página ia sendo terminada, era levada às escolas envolvidas no projeto com o propósito de se avaliar a legibilidade do material pelos alunos.

Na primeira página: "Representação da Terra", modificada muitas vezes, por conta da busca dessa legibilidade, foram utilizados um planisfério, a fotografia de um globo e a imagem de um satélite. 0 objetivo, ao aplicar essa página, era constatar se 0 aluno reconhecia as várias formas de representação da Terra. $\mathrm{N}$ as salas de terceira e quarta séries 0 globo e o planisfério puderam ser considerados as formas mais conhecidas de representação espacial.

A segunda página, "O nde estamos na Terra", que inseria o município de Rio Claro no planisfério, trouxe uma seqüência de mapas: planisfério, o Brasil na América, o estado de São Paulo no Brasil, a região de Campinas no estado de São Paulo, o município de Rio Claro na região de Campinas e o município de Rio Claro. Para melhor visualizar o Brasil na América foi preciso contornar o território brasileiro. 
As reuniões realizadas no Laboratório de Ensino de G eografia, do D epartamento de Educação do Instituto de Biociências de Rio Claro, em todas as quintas-feiras dos anos de 1997, 1998 e dos meses de janeiro, fevereiro, março e abril de 1999, foram importantes porque ali não só se produziram as temáticas das páginas do atlas; elaboraram-se também as atividades de ensino para as classes envolvidas no projeto: duas classes de terceira e quarta séries e duas de quinta e sexta séries, nas quais eu lecionava na Escola Estadual "Professora H eloísa Lemenhe M arasca".

Antes da aplicação das duas primeiras páginas, avaliações de lateralidade e da planta da sala de aula foram realizadas pelo estagiário Adriano Rodrigo de O liveira porque, segundo O liveira (1977), é necessário que a criança tenha adquirido a noção das relações projetivas de ordem espacial para iniciar o trabalho com mapas e, para Ferreira \& M artinelli (1995), o ambiente mais adequado para a construção do espaço pelas crianças é a sala de aula, que deve ser representado por elas, e é da sala de aula que se vai à representação da escola para que se mantenha a continuidade espacial.

A reflexão sobre as minhas práticas, as mudanças de postura diante de mim mesma e dos meus alunos provocavam um desafio cada vez maior. Vivenciava intensamente esse Projeto Atlas. Em casa, na escola, no grupo, pensamentos dançavam na mente: da planta da sala de aula e da escola chega-se aos mapas do bairro, da cidade e do município!

Fascinava-me esse trabal ho de rever, reler e lembrar, por meio da pesquisa, fatos e imagens que estavam nas minhas lembranças de menina, nas histórias contadas pela minha mãe, poetisa nata; pela minha avó materna, que veio menina de Portugal, filha do "C hegadinho", Arthur Diniz de Carvalho, figura carismática e muito caridosa, dono de um hotel próximo da matriz de São J oão Batista; e da professora Cida Bilac Jorge que, em seu poema Pórtico, tão bem colocara: Aqui foi sesmaria do M orro Azul, sesmaria do Ribeirão Claro, Curral dos Pereira, porta para o sertão que os bandei rantes buscavam... que iam se esboçando nesse "objeto de ensino".

M uitas dificuldades surgiram quando se iniciou a construção da página da D ivisão Político-Administrativa do município porque a Prefeitura de Rio Claro não possuía uma carta topográfica atualizada. O s limites municipais dessa carta nem sequer estavam bem definidos e, para surpresa nossa, o limite sudeste do município de Rio Claro estava incorreto, principalmente nos mapas municipais que circula- 
vam pelas salas de aula nas escolas. Limeira já contava naquela época com materiais prontos e atualizados porque a Prefeitura já possuía um melhor banco de dados, razão pela qual a produção das páginas de seu atlas se fazia mais rapidamente.

Era preciso buscar uma base para o mapa municipal de Rio Claro. Com o IBGE tentei obter as cópias da Carta do Brasil de 1969, na escala de 1:50.000, das folhas de Araras, Corumbataí, I tirapina, Leme, Limeira, Rio Claro e Piracicaba para a construção desse mapa.

$\mathrm{N}$ ovas dificuldades surgiram porque só se conseguiam cópias xerografadas, de má qualidade quanto à nitidez. Algumas cartas topográficas não estavam disponíveis na agência local do IBGE e se teve que aguardar por cópias vindas de Piracicaba. Algumas, já esgotadas, precisaram ser buscadas em outras cidades ou até mesmo em São Paulo. Ao final de meses, o mapa ficou pronto.

Problema maior ocorreu com a construção da malha urbana, pois a planta disponível na Prefeitura de Rio Claro era uma cópia feita em sistema heliográfico, datada de 1984. Era 1998! Esse sistema dificultava a escanerização do material para uma possível base digitalizada, com a representação dos mais de cem bairros da cidade.

Surgia também nas reuniões a proposta de elaboração de um guia didático. Era preciso detalhar os temas apresentados em cada uma das páginas para que outros professores, que mais tarde fossem utilizar 0 atlas, pudessem apreender todos os procedimentos adotados durante a sua construção. Era preciso levantar fontes bibliográficas, dados, fotos, documentos para que se pudesse organizar o material. Era preciso pensar nas aulas que iriam anteceder a aplicação das páginas que iam ficando prontas e era preciso acompanhar a produção gráfica das páginas.

N ovas reflexões... "Ler significa reler e compreender, interpretar. Cada um lê com os olhos que tem. E interpreta a partir de onde os pés pisam" (Boff, 1997).

N ovas buscas. - Respirem Atlas, dizia a professora Rosângela. Eu pensava: - Sonhar é possível... Pés no chão... M as e o Atlas? Sairia? O sonho tornar-se-ia realidade? Esperança!

A página de Relevo, que mais tarde possibilitou a construção do mapa da Divisão Político-Administrativa do M unicípio de Rio Claro, contém as diferenças de altitude da região e suas bacias hidrográficas. 0 mapa foi feito a partir das folhas da Carta do Brasil do IBGE, na escala de 1:50.000, e teve como referências, para a deli- 
mitação e hidrografia, os limites intermunicipais e as curvas de nível. Em conjunto com a professora Rosângela, foram escolhidas as cotas altimétricas, bem como os pontos que deveriam ser selecionados, como as serras, os morros, os rios e os córregos.

0 entorno do município estava pronto e era preciso elaborar os textos que acompanhariam o mapa e buscar fotos que levassem os alunos a identificar os lugares mais significativos dentro desses limites municipais, bem como construir o perfil topográfico para fechar a página.

Assim, a confluência de rios importantes na região, a área urbana cortada por um córrego canalizado, que modificou o traçado da malha urbana gerando inúmeros problemas, principalmente aqueles relacionados às enchentes, e $0 \mathrm{H}$ orto Florestal foram fotografados para compor a página do relevo.

Concretizava-se o que havia lido sobre as três formas de linguagem que poderiam estar integradas nos atlas escolares porque o mapa, a fotografia e o texto escrito despertavam um interesse cada vez maior dos meus alunos pelos conteúdos que estavam sendo trabalhados pelo G rupo Atlas e eles demonstravam curiosidade pelas novas páginas que seriam aplicadas em sala de aula.

Utilizou-se, portanto, a mesma base do mapa de relevo para 0 mapa da Divisão Político-Administrativa do M unicípio. N ele estão os 3 distritos: 0 da sede municipal e 0 das vilas de Ajapi e Assistência, os bairros rurais de Batovi, I tapé e Ferraz e os 25 núcleos rurais: pequenos aglomerados com poucos habitantes, com menos de 50 casas, que podem ter uma capela modesta ou uma escola do primeiro ciclo do ensino fundamental, um bar ou uma venda e onde se pode encontrar um telefone público.

A área urbana inserida nesse mapa foi feita a partir de uma imagem de satélite Spot de 1995, em falsa cor e preto e branco, cedida pela professora M aria Isabel de Freitas, do D epartamento de Cartografia da unESP de Rio Claro.

O objetivo, ao aplicar essa página, era avaliar se o aluno reconhece o município de Rio Claro, identificando a zona rural e a área urbana, os distritos, os bairros e núcleos rurais, bem como os municípios vizinhos e a sua localização com relação ao município de Rio Claro.

0 mapa da Rede Viária foi atualizado a partir de um outro mapa contido em Lima (1994) e, durante a sua aplicação nas salas de aula, as dificuldades apresentadas estiveram relacionadas às rodovias municipais, que são numeradas e que mudam de numeração em alguns tre- 
chos. Porém, era a primeira vez que os alunos viam um mapa do município com o traçado de ferrovias, rodovias, caminhos ou trilhas e era muito difícil associar a letra, o número e o nome das rodovias.

Q uanto ao tema Saúde, buscou-se a localização dos hospitais e das unidades básicas de saúde para que o técnico Fabrício Luiz da Silva M orais, da Cartografia D igital, pudesse lançá-los nos diversos setores da malha urbana. A professora Lígia Brochado de Aguiar, da área de Ciências, responsabilizou-se pelo texto escrito e pelos gráficos da página. Após o teste de legibilidade durante a aplicação nas escolas, esses gráficos foram substituídos por um organograma do Sistema Ú nico de Saúde.

A cidade dividida em Setores foi representada por meio de um agrupamento feito a partir de uma classificação da Secretaria M unicipal de Planejamento e M eio Ambiente da Prefeitura M unicipal de Rio Claro, de 1991, que continha uma divisão da área urbana com base em três critérios de classificação: por região (orçamento participativo), por bairros (mais de cem) e pela renda do chefe de família do C enso de 1991, em que os setores eram classificados em sete categorias.

A análise dos dados desse mapa possibilitou um agrupamento dos bairros pela sua proximidade ou pela renda média do chefe de família, visto que muitas vezes bairros muito próximos tinham rendas altamente discrepantes. Assim surgiram os 23 setores que possibilitaram a representação das páginas dos Bairros de Rio Claro, onde estão inseridos todos os serviços públicos e as escolas da cidade.

A página de Serviços foi feita a partir da coleta de dados sobre os serviços de responsabilidade da administração pública municipal, estadual e federal, bem como de alguns outros que atualmente estão privatizados, como a Telefônica e a Elektro. 0 ptou-se por não colocar os demais órgãos públicos municipais porque se colocariam muitas informações nos setores em que se dividiu a cidade, o que dificultaria a sua visibilidade pelos leitores.

A página de Escolas foi a que nos deu mais trabalho para organizar porque havia somente uma listagem das escolas estaduais, municipais e particulares e foi preciso levantar o local exato de cada uma delas, para que a sua localização não ficasse incorreta.

M uitas vezes tentou-se obter as informações via telefone, mas pessoas que trabal havam nas próprias escolas não sabiam os seus endereços. Foi preciso checar pessoalmente a localização de cada uma delas, principalmente daquelas localizadas mais distante do centro. 
Todo esse trabalho possibilitou a representação de todas as escolas nos mapas dos bairros. $M$ as justamente no momento em que fomos, o técnico e eu, colocar o símbolo da escola em que eu lecionava, não havia o arruamento, isto é, a base da malha urbana. Era preciso buscar soluções para localizar os serviços existentes no trecho que faltava nesse setor.

A Secretaria de Planejamento e M eio Ambiente do M unicípio de Rio Claro cedeu-nos as fotos aéreas dessa área da cidade para podermos representar os dois estabelecimentos de ensino que ali estão localizados. A disponibilidade da representação da cidade de Rio Claro por meio de fotografias aéreas aconteceu quando o projeto havia terminado e as páginas do Atlas M unicipal Escolar de Rio Claro estavam prontas.

Para compensar todo esse trabalho, foi gratificante vivenciar a reação dos meus alunos da Escola Estadual "Professora H eloísa Lemenhe M arasca" ao reconhecerem, durante a aplicação da página do Setor Bela Vista, o bairro da escola, ao nomearem no mapa as ruas e as avenidas, ao localizarem por meio da foto aérea do bairro 0 posto de combustível, o supermercado e até mesmo as suas residências, assinalando o trajeto casa-escola.

O Atlas M unicipal Escolar de Rio Claro é hoje uma realidade. Lançado em agosto de 2002, ele está nas salas de aula de terceiras e quartas séries da rede de ensino municipal como um novo "objeto de ensino" ou um "artefato", como prefere a professora Rosângela.

0 Grupo Atlas continua se reunindo às quintas-feiras. Atualmente é um grupo maior que se debruça sobre as práticas docentes de outros professores-pesquisadores. Suas aulas de H istória, Geografia e Ciências são acompanhadas pelos autores do atlas, hoje denominados professores-tutores, com a finalidade de se problematizar sobre as práticas docentes de cada um deles e sobre a aprendizagem de seus alunos.

Recebido em abril de 2003 e aprovado em maio de 2003.

\section{N ota}

1. A professora M ônica C ristina Q ueiroz Chistofoletti, da terceira série da Escola M unicipal de Educação Infantil e Ensino Fundamental "Antonio M aria M arrote", professora-pesquisadora da fase II do Projeto Integrando U niversidade e Escola por meio de uma Pesquisa 
em Colaboração, ao refletir sobre uma atividade de ensino realizada no segundo semestre de 2002, na qual utilizara uma das páginas do Atlas M unicipal Escolar de Rio Claro, comentou perplexa: "O mapa é um texto!"

\section{Referências bibliográficas}

ALM EID A, R.D. U ma proposta metodológica para a compreensão de mapas geográficos. 1994. 289f. Tese (D outorado em Educação) - Faculdade de Educação, U niversidade de São Paulo, São Paulo.

ALM EID A, R.D .; PASSIN I, E.Y. 0 espaço geográfico: ensino e representação. São Paulo: Contexto, 1989.

BERTIN , J.; GIM EN O, R. A lição de cartografia na escola elementar. Boletim Goiano de G eografia, G oiânia, v. 2, n. 1, jan./jun. 1982.

BILAC, M .A.O. Poemas azuis. Rio Claro: Arquivo Público e HistóriCO, 1984.

BOFF, L. A águia e a galinha. Petrópolis: Vozes, 1997.

LIM A, M . A. Avaliação da qualidade ambiental de uma microbacia no município de Rio Claro. 1994. 264f. Tese (D outorado em Geografia) - Instituto de Geociências e Ciências Exatas, Universidade Estadual Paulista Júlio de M esquita Filho, Rio Claro.

M ARTIN ELLI, M .; FERREIRA, G.M.L. A cartografia para os atlas geográficos para crianças. In: COLOQ UIO Cartografia para Crianças, 1., Rio Claro, 1995. Anais.. Rio Claro: UnESP/USP, 1995. p.37-40.

O LIVEIRA, L. Estudo metodológico e cognitivo do mapa. 1977. $234 f$. Tese (Livre docência) - Instituto de G eociências e Ciências Exatas, Universidade Estadual Paulista Júlio de M esquita Filho, Rio Claro.

SÃO PAU LO . Secretaria Estadual de Educação. Proposta pedagógica curricular para o ensino de geografia: 1o grau. São Paulo: SEE/CENP, 1992. 